Cahiers $d u$ MONDE RUSSE

\section{Cahiers du monde russe}

Russie - Empire russe - Union soviétique et États indépendants

$50 / 2-3 \mid 2009$

L'Europe orientale, 1650-1730. Crises, conflits et renouveau

\title{
Crisis, Revolution, and Russian JewsJonathan FRANKEL
}

, Cambridge, MA : Cambridge University Press, 2009, 324 p.

\section{Claire Le Foll}

\section{(2) OpenEdition}

\section{Journals}

\section{Édition électronique}

URL : https://journals.openedition.org/monderusse/9783

DOI : 10.4000/monderusse. 9783

ISSN : $1777-5388$

\section{Éditeur}

Éditions de l'EHESS

\section{Édition imprimée}

Date de publication : 15 septembre 2009

ISBN : 978-2-7132-2260-3

ISSN : $1252-6576$

\section{Référence électronique}

Claire Le Foll, « Crisis, Revolution, and Russian Jews Jonathan FRANKEL », Cahiers du monde russe [En ligne], 50/2-3 | 2009, mis en ligne le 14 janvier 2013, consulté le 03 septembre 2022. URL : http:// journals.openedition.org/monderusse/9783; DOI : https://doi.org/10.4000/monderusse.9783

Ce document a été généré automatiquement le 3 septembre 2022

Tous droits réservés 


\section{Crisis, Revolution, and Russian JewsJonathan FRANKEL}

, Cambridge, MA : Cambridge University Press, 2009, 324 p.

Claire Le Foll

Jonathan FRANKEL, Crisis, Revolution, and Russian Jews,
Cambridge, MA : Cambridge University Press, 2009, 324 p.

1 Il s'agit de la dernière contribution de Jonathan Frankel à l'histoire des juifs de Russie. Publié peu après sa mort en mai 2008, ce recueil d'essais fut cependant préparé par ses soins. Il regroupe onze de ses principaux articles, écrits à différentes périodes de sa carrière, et permet de mesurer la portée du travail de l'un des plus grands historiens des juifs russes. Né à Londres en 1935 de parents immigrés d'Europe centrale, Jonathan Frankel découvrit l'histoire russe à Cambridge et consacra sa thèse à l'émergence des mouvements politiques parmi les juifs russes à la fin du XIX ${ }^{e}$ siècle. Il s'installa en Israël en 1964 où il enseigna à l'université hébraïque de Jérusalem jusqu'à sa retraite en 2004. Son premier ouvrage et véritable opus magnum, Prophecy and Politics, est devenu un classique incontournable pour qui veut comprendre les origines idéologiques et le développement historique des principaux mouvements politiques juifs russes du tournant $\mathrm{du} \mathrm{xx}^{\mathrm{e}}$ siècle ${ }^{55}$. Cette étude du socialisme et du nationalisme juifs offre une analyse détaillée et subtile à la fois des idées politiques et des organisations, des hommes et des événements. Suite à ce travail qui érigeait la vague de pogroms de 1881-1882 en tournant majeur de l'histoire juive russe, Frankel s'intéressa à une autre crise de l'histoire juive, l'affaire de Damas, liée à une accusation de crime rituel ${ }^{56}$. Il fut également l'éditeur de la plupart des vingt volumes de la série de recueils thématiques «Studies in Contemporary Jewry ». À même de lire des sources en russe, yiddish, hébreu, anglais, français et allemand, il produisit des travaux historiques fondamentaux pour l'histoire juive contemporaine dans son ensemble et posa plus spécifiquement un regard éclairé et subtil sur l'histoire juive russe, ainsi que Crisis, Revolution, and Russian Jews en témoigne. 
2 Les articles regroupés ici ont tous trait au thème majeur de la recherche de Frankel : la vie politique juive moderne et les différentes formes et tournants qu'elle a pris, principalement dans l'Empire russe. C'est en effet le caractère radical et souvent révolutionnaire des mouvements politiques juifs nés en Europe orientale qui l'intéressa, davantage que les mouvements politiques libéraux et émancipationnistes, prédominants en Europe occidentale. Sa réflexion sur la radicalité politique des juifs russes s'articule autour de trois thèmes : connexion et différences entre modèle occidental « libéral » et modèle oriental « radical»; rôle de l'intelligentsia; impact des crises. Ces textes montrent que ses thèses, quoique critiquées dans des travaux plus récents, se révèlent aussi originales que solides et fécondes.

3 On doit d'abord à Frankel d'avoir mis en évidence non seulement les différences fondamentales entre la vie politique juive en Russie et en Europe occidentale, mais aussi les échanges et influences mutuels qui les liaient. Cette circulation des idées et de l'information entre Amérique, Europe occidentale et orientale est évidente à la lecture du chapitre II sur la réception dans la presse de la naissance de l'Alliance israélite universelle (AIU) en 1860. Cette étude fait également apparaître la force de l'idéal émancipationniste parmi les juifs d'Europe occidentale. L'AIU, qui avait pour but d'unir le peuple juif dans le monde, n'apparut pas à l'intelligentsia juive comme une menace pour l'intégration des juifs dans leur pays respectif. Au contraire, elle joua un rôle décisif pour rallier l'opinion publique à la défense des communautés juives persécutées et encourager les juifs à participer à la société environnante en tant que citoyens égaux et loyaux. Si la Haskalah (Lumières juives) eut également de nombreux adeptes à l'Est et l'AIU des équivalents en Russie, l'idéal libéral n'y fut pas aussi prospère qu'à l'Ouest. Ce sont ces déviations de plus en plus puissantes du modèle émancipationniste en Russie que Frankel étudie. En comparant deux situations de crise - l'affaire de Damas en 1840 et les pogroms de 1881-1882 -, il met en évidence cette ligne de fracture entre Ouest et Est (ch. I). Alors que l'affaire de Damas ne parvint pas à ébranler la croyance en l'idéal d'assimilation et d'émancipation en Europe occidentale, la vague de pogroms de 1881 marque à ses yeux un tournant dans l'histoire des juifs de Russie qui pour la plupart abandonnèrent l'idéal d'assimilation et se tournèrent vers des solutions de rupture révolution, nationalisme, exil. Si Frankel consacra l'essentiel de ses recherches à l'étude de cette radicalité politique des juifs russes, il ne cessa également de s'interroger sur l'impact et la fécondité des relations qui unissaient ce qu'il voyait comme deux soussystèmes politiques indissociables. Frankel analyse dans le chapitre X l'œuvre historique de Simon Dubnov et de ses successeurs dans le contexte de cette dichotomie entre Est et Ouest. Il montre que la vision historique de Dubnov s'est construite contre le modèle libéral ouest-européen. Bien qu'émancipés et dotés de droits égaux, les juifs d'Europe occidentale étaient à ses yeux en train de disparaître en tant que peuple et que nation. C'est afin de lutter contre ce processus d'assimilation qui risquait d'aboutir à la désintégration de l'identité juive que Dubnov entreprit d'écrire une histoire du peuple juif mettant en avant la spécificité et la force de l'organisation communautaire juive et du mysticisme juif (hassidisme). Dans cette vision historique bâtie sur une bipolarité opposant forces centripètes et centrifuges, désintégration et solidarité ou assimilation et communauté, les moments de crise étaient perçus comme des catalyseurs de l'unité et de la solidarité du peuple juif. La déconstruction de ce paradigme historiographique dubnovien, devenu la doxa des générations d'historiens suivantes, ne met que mieux en relief l'émergence à partir des années 1980 d'une nouvelle historiographie basée sur le concept de multiplicité et non plus de bipolarité. 
4 Frankel fit la part belle au rôle de l'intelligentsia et aux débats idéologiques. Trois chapitres sont ici consacrés aux prises de position d'intellectuels juifs majeurs : Sh. AnSky (IV), Yosef Haim Brenner (V) et Simon Dubnov (X). Si les articles consacrés à Brenner et Dubnov sont des explorations brillantes mais académiques des oscillations idéologiques et du rôle dans l'histoire politique juive du début $\mathrm{du} \mathrm{xx}^{\mathrm{e}}$ siècle de ces intellectuels, l'article sur An-Sky est une tentative plus originale d'utiliser des œuvres littéraires comme source historique pour mieux comprendre comment la révolution de 1905 fut vécue au quotidien dans « la rue juive », selon l'expression yiddish. Cette analyse comparée d'un roman de An-Sky (In Shtrom [Dans la tempête]) et de quatre autres romans contemporains fait apparaitre des points communs dans la manière dont l'événement fut représenté dans la littérature, mais aussi les divergences idéologiques nées de 1905 parmi les intellectuels juifs. Les cinq œuvres en question mettent l'accent sur l'euphorie et l'excitation qui précédèrent octobre 1905 et se traduisirent par une mobilisation politique sans précédent de la population juive en général. C'est cependant le rôle proéminent de la jeunesse juive, des femmes en particulier, qui est mis en avant dans ces romans. La révolte de la jeunesse aboutit dans cette littérature à des conflits intergénérationnels violents qui s'avérèrent indépassables ou qui, comme chez An-Sky, furent surmontés dans un mouvement de réconciliation autour de la cause juive et d'autodéfense contre les pogromistes.

5 Hormis ces études biographiques et littéraires qui font une large place aux volte-face et tergiversations idéologiques individuelles, le recueil contient plusieurs sections très éclairantes sur les débats politiques qui ont opposé ou divisé les camps sioniste et bundiste. Le chapitre VII est une mise en perspective historique de l'opposition des socialistes au sionisme avant et après la Première Guerre mondiale. Frankel y apporte des éléments essentiels à la compréhension de la haine nourrie par les bundistes contre les sionistes, tout en montrant que l'opposition ne fut pas toujours systématique et univoque : de nombreux hommes politiques changèrent de camp, alors que d'autres, tel Ber Borokhov, tentèrent de réconcilier, idéologiquement et politiquement, marxisme et sionisme. Frankel propose également une synthèse nuancée de l'histoire complexe et oscillante de l'antisionisme en Union soviétique. Il examine (ch. VIII) les divergences idéologiques autour du projet sioniste au travers des débats ayant accompagné la publication d'un livre-mémorial, Yizkor, en 1911, en Palestine, destiné à rendre hommage aux colons et soldats morts pendant des confrontations avec les Arabes. L'auteur rappelle que, dès 1911, la guerre contre les Arabes avait provoqué une polémique : indispensable pour certains dans sa dimension historique autant que mythologique, celle-ci était perçue comme inacceptable par ceux qui prônaient une fraternité sémite. Le «problème sioniste » et la question arabe divisèrent également les socialistes émigrés en Amérique (ch. IX). La double position idéologique des bundistes américains - anti-communiste et anti-sioniste - les obligea à adopter des positions bancales qui les affaiblirent, notamment à propos de la responsabilité des Arabes dans les incidents qui se produisaient en Palestine et de la réponse à apporter à la destruction des juifs d'Europe lors de la Conférence juive américaine de 1943.

6 Le troisième axe de réflexion concerne la notion de crise et son impact sur l'histoire des juifs russes. Trois chapitres y sont consacrés. Outre les crises de 1840 et 1881 déjà mentionnées (ch. I), la révolution de 1905 questionna largement l'historien. De manière surprenante, Frankel parvint à la conclusion que celle-ci ne fut pas un événement aussi important que 1881 et ne modifia pas fondamentalement le paysage politique juif russe 
(ch. III). À ses yeux, cette révolution permit de diffuser plus largement des idées politiques qui circulaient déjà auparavant et de faire émerger une génération nouvelle d'hommes politiques et de formations politiques inédites, mais elle n'apporta pas d'idées ou de valeurs originales. Enfin le chapitre VI est consacré à la période extrêmement complexe qui s'étend de la Première Guerre mondiale à la fin de la guerre civile (1914-1921). Souvent négligée par les spécialistes d'histoire juive, cette longue crise s'avère cependant plus cruciale que celle de 1881, car elle aurait mis fin, selon Frankel, à un siècle environ de relative prospérité pour le peuple juif. L'historien rappelle en effet que pendant le $\mathrm{XIX}^{\mathrm{e}}$ siècle, les juifs d'Europe connurent un " âge d'or » : égalité en droits accordée partout en Europe sauf en Russie et Roumanie, paix et croissance économique engendrèrent un fort accroissement démographique. Malgré la persévérance d'un antisémitisme traditionnel et l'émergence de formes modernes de judéophobie, Frankel considère que l'antisémitisme politique était en perte de vitesse à la veille de la guerre. Les morts, destructions et déplacements de populations qui se succédèrent de 1914 à 1921 bouleversèrent donc durablement la vie juive. Les actes d'antisémitisme atteignirent un seuil sans précédent et la méfiance envers la "puissance juive» devint un mythe instrumentalisé à des fins politiques aussi bien à l'Ouest qu'à l'Est de l'Europe. Bien que la période ait également démontré la solidarité des communautés juives et se soit achevée sur une note d'espoir puisque les juifs faisaient partie des minorités protégées par les traités de paix et avaient acquis un statut favorable dans la plupart des États européens, elle était porteuse de la guerre suivante et de dangers à venir encore plus terribles pour les juifs.

7 Ce recueil vient à point nommé rappeler la valeur inestimable du travail de Frankel pour comprendre les débats idéologiques et les transformations profondes de la vie politique juive russe à partir de la fin du xIX ${ }^{e}$ siècle. Grâce à sa modération politique et à sa capacité à dépasser tous les cloisonnements - entre histoire des idées et histoire institutionnelle, historiographie israélienne pro-sioniste et diasporique anti-sioniste, histoire des juifs d'Europe occidentale et d'Europe orientale, histoire russe et histoire juive - , cet auteur a posé les jalons d'une histoire politique et intellectuelle des juifs russes non idéologique. Cependant, un certain nombre d'historiens de la nouvelle génération lui ont reproché - Frankel le reconnaît d'ailleurs lui-même dans l'introduction - de ne donner qu'un éclairage partiel de la réalité puisqu'il fait la part belle aux intellectuels et aux périodes de crise, mais néglige les processus sociaux et économiques, la vie quotidienne ainsi que les continuités historiques. Assumant ses choix, les légitimant par son parcours personnel et ses convictions d'historien, Frankel rappelle que l'écriture de l'histoire doit intégrer les facteurs évolutionnistes et révolutionnaires et laisse à d'autres le soin de compléter le tableau et de regarder l'histoire juive russe sous un autre angle. 


\section{NOTES}

55. Prophecy and Politics: Socialism, Nationalism and the Russian Jews, 1862-1917, Cambridge, MA : Cambridge University Press, 1981.

56. The Damascus Affair: "Ritual Murder", Politics, and the Jews in 1840, Cambridge, MA: Cambridge University Press, 1997. 